\title{
Photocatalytic Decomposition of Amoxicillin Trihydrate Antibiotic in Aqueous Solutions under UV Irradiation Using $\mathrm{Sn} / \mathrm{TiO}_{2}$ Nanoparticles
}

\author{
Robab Mohammadi, ${ }^{1}$ Bakhshali Massoumi, ${ }^{2}$ and Mohammad Rabani ${ }^{1}$ \\ ${ }^{1}$ Department of Chemistry, Islamic Azad University, North-Tehran Branch, P.O. Box 3155636951, Tehran 1477893855, Iran \\ ${ }^{2}$ Department of Chemistry, Payame Noor University, P.O. Box 19395-3697, Tehran 196569-19395/4697, Iran \\ Correspondence should be addressed to Robab Mohammadi, mohammadi_rb@yahoo.com
}

Received 16 December 2011; Accepted 28 December 2011

Academic Editor: Jiaguo Yu

Copyright ( $) 2012$ Robab Mohammadi et al. This is an open access article distributed under the Creative Commons Attribution License, which permits unrestricted use, distribution, and reproduction in any medium, provided the original work is properly cited.

$\mathrm{TiO}_{2}$ and $\mathrm{Sn} / \mathrm{TiO}_{2}$ nanoparticles were successfully synthesized by sol-gel method. The resulting nanoparticles were characterized by XRD, TEM, SEM, UV-Vis reflectance spectroscopy, and BET analysis methods. The effects of Sn-doping on the crystal structure, surface area, adsorption properties, pore size distribution, and optical absorption properties of the catalysts were investigated. The effect of different Sn content on the amount of hydroxyl radical was discussed by using salicylic acid as probe molecule. The photocatalytic activity of samples was tested by photocatalytic mineralization of amoxicillin trihydrate (AMOX) as a model pollutant. $\mathrm{Sn} / \mathrm{TiO}_{2}$ nanoparticles exhibited high photocatalytic activity during the mineralization of AMOX under UV light due to increase in the generated hydroxyl radicals, band gap energy, specific surface area, and decrease in the crystallite size. The kinetic of the mineralization of AMOX can be explained in terms of the Langmuir-Hinshelwood model. The values of the adsorption equilibrium constant $\left(K_{\mathrm{AMOX}}\right)$ and the kinetic rate constant of surface reaction $\left(k_{\mathrm{c}}\right)$ were $0.56\left(\mathrm{mg} \mathrm{L}^{-1}\right)^{-1}$ and $1.86 \mathrm{mg} \mathrm{L}^{-1} \mathrm{~min}^{-1}$, respectively.

\section{Introduction}

Recently, there has been an increasing concern, particularly in highly developed countries, about penetration of pharmaceuticals into the environment and related risks [1]. A large variety of pharmaceutical compounds have been frequently found in sewage treatment plant effluents and river streams at concentrations up to several $\mu \mathrm{g} \mathrm{L}{ }^{-1}$ [2]. These compounds enter the aquatic environment after their ingestion and subsequent excretion either without modifications or in the form of nonmetabolized parent compounds [3]. Among the various pharmaceutical compounds present in the environment, special emphasis has been given to antibiotics, which are the most often discussed pharmaceuticals because of their potential role in the development of antibioticresistant bacteria [4]. The great concern is that waters contaminated with antibiotics can reach waters used for human consumption or municipal water treatment facilities [5]. Due to their antibacterial activity, waters containing antibiotics commonly used in animal and human health (antibiotics included) are refractory to natural biological degradation or conventional wastewater treatments [6]. Amoxicillin is a semisynthetic $\beta$-lactam antibiotic (7-[2amino-2-(4-hydroxyphenyl)-acetyl] amino-3,3-dimethyl-6oxo-2-thia-5-azabicyclo [3.2.0] heptane-4-carboxylic acid), used in humans and food-producing animals to treat several diseases. Some authors have found amoxicillin and cloxacillin in wastewater [7].

Several alternatives to destroy these kinds of compounds have been considered in recent studies in the literature. These include reverse osmosis, adsorption on activated carbons, or advanced oxidation technologies, such as Fenton reaction, ozonation, and peroxidation combined with UV light [8]. Heterogeneous photocatalysis using a semiconductor is a new, effective, and rapid technique for the removal of pollutants from water [9]. Among various semiconducting materials, much attention has been given to $\mathrm{TiO}_{2}$ due to its outstanding stability, inexpensiveness, lack of toxicity, and strong photoactivity [10]. Extensive researches have been focused on synthetic methods of semiconductor 
TABLE 1: Chemical structure and characteristics of AMOX.

\begin{tabular}{ll}
\hline & Characteristics \\
\hline IUPAC name & $\begin{array}{l}(2 \mathrm{~S}, 5 R, 6 R)-6 \text {-[(R)-(-)-2-amino-2-( } p \text {-hydroxyphenyl)acetamido]-3,3-dimethyl-7-oxo-4thia-1- } \\
\text { azabicyclo[3.2.0]heptane-2-carboxylic acid trihydrate } \\
\text { Molecular formula }\end{array}$ \\
$\begin{array}{l}\text { Molecular weight } \\
\text { Appearance }\end{array}$ & 419.45 \\
Welting point & White or almost white powder
\end{tabular}

nanoparticles with better crystallinity and photocatalytic performance. Yu et al. [11] prepared $\mathrm{CuO} / \mathrm{Cu}_{2} \mathrm{O}$ composite hollow microspheres with controlled diameter and composition and without the addition of templates and additives by hydrothermal synthesis using $\mathrm{Cu}\left(\mathrm{CH}_{3} \mathrm{COO}\right)_{2} \cdot \mathrm{H}_{2} \mathrm{O}$ as a precursor. However, there is still a problem that photocatalytic efficiency is not high because recombination of photogenerated electron-hole pairs influences low photo quantum efficiency [12]. To enhance its photoactivity, $\mathrm{TiO}_{2}$ is often doped with various metal ions and oxides such as $\mathrm{Zn}, \mathrm{Pt}, \mathrm{Pd}, \mathrm{Au}, \mathrm{Ag}$, $\mathrm{Cu}, \mathrm{WO}_{3}$, and $\mathrm{V}_{2} \mathrm{O}_{5}$ [13]. The dopants act as charge separators of photoinduced electron-hole pairs, and it is proposed that, after excitation, the electron migrates to the metal where it becomes trapped and electron-hole recombination is suppressed [14]. Castro et al. [15] presented the performance of $\mathrm{Ag}-\mathrm{TiO}_{2}$ photocatalyst, obtained using the hydrothermal synthesis route, under different light irradiations setups such as solar-simulated and interior-lighting lamps with different irradiation powers, towards the photocatalytic inactivation of $E$. coli in water. A possible way to improve the photocatalytic performance of doped $\mathrm{TiO}_{2}$ is to explore the cooperative effect by introducing more than one species of foreign elements to the host [16]. Appropriate choice of the codoping pair is the key factor. Li et al. [17] investigated the structural and electronic properties of iron-fluorine ( $\mathrm{Fe}-$ F) and iron-sulfur- (Fe-S-) codoped anatase $\mathrm{TiO}_{2}$. They reported that the photocatalytic performance under visible light of $\mathrm{Fe}-\mathrm{S}$-codoped $\mathrm{TiO}_{2}$ is better than that of $\mathrm{Fe}-\mathrm{F}-$ codoped one, and $\mathrm{Fe}-\mathrm{S}$ should be a better codoping pair.

Photocatalytic oxidation of some antibiotics such as Lincomycin, tetracycline, oxolinic acid, and fluoroquinolone has been reported [2, 18-20]. Xekoukoulotakis et al. [4] have reported that the use of $\mathrm{UV} / \mathrm{TiO}_{2}$ was able to achieve $90 \%$ TOC reduction after $90 \mathrm{~min}$ of reaction with $10 \mathrm{mg} \mathrm{L}^{-1} \mathrm{ERM}$ and $250 \mathrm{mg} \mathrm{L}^{-1} \mathrm{TiO}_{2}$. Abellán et al. [21] have reported $82 \%$ of sulfamethoxazole degradation and $23 \%$ TOC reduction by $\mathrm{UV} / \mathrm{TiO}_{2}$ in $6 \mathrm{hr}$. No study on photocatalytic oxidation of amoxicillin $\cdot 3 \mathrm{H}_{2} \mathrm{O}$, in aqueous solution using $\mathrm{Sn} / \mathrm{TiO}_{2}$ as a catalyst under UV-C irradiation has been reported.
In this work, preparation and characterization of pure and $\mathrm{Sn} / \mathrm{TiO}_{2}$ nanoparticles is reported. These nanosized catalysts were characterized by the techniques such as XRD, SEM, TEM, DRS, and BET analysis methods. The photocatalytic activity of the prepared nanoparticles has been studied on the mineralization of AMOX, as a prototype molecule. Chemical structure and characteristics of AMOX have been given in Table 1 . We investigated in a systematic way the effect of various parameters such as doping content of Sn, the amount of photocatalyst, and AMOX initial concentration on mineralization in model aqueous solutions. A detailed kinetic description of the process was given based on well-known mechanistic/kinetic models, namely, the Langmuir-Hinshelwood (L-H) model whereby the organic regent was preadsorbed on photocatalyst surface prior to UV illumination. We intentionally decided to investigate sample mineralization rather than substrate decomposition since the rationale of micropollution abatement in aqueous matrices should involve its complete elimination rather than its transformation to other species.

\section{Experimental}

2.1. Materials. Titanium n-butoxide (TBOT, $\left.\mathrm{Ti}\left(\mathrm{OC}_{4} \mathrm{H}_{9}\right)_{4}\right)$, ethanol with absolute grade, and tin (IV) chloride were used without any further purification. All chemicals used in this study were analytical grade and purchased from Merck (Germany).

2.2. Preparation of $\mathrm{TiO}_{2}$ and $\mathrm{Sn} / \mathrm{TiO}_{2}$ Nanoparticles. According to $[22,23]$, for the synthesis of $\mathrm{TiO}_{2}$ nanoparticles, first titanium n-butoxide was slowly dissolved in ethanol. The prepared solution was sonicated in an ultrasonic bath. The hydrolysis process was then performed by adding of drop by drop $\mathrm{H}_{2} \mathrm{O}$ into a flask containing TBOT/EtOH mixture under reflux and magnetic stirring. The molar ratio of TBOT/EtOH/ $\mathrm{H}_{2} \mathrm{O}$ was $1: 1: 65$. The yellowish transparent sol was yielded after continuously stirring for $3 \mathrm{~h}$. Finally, $\mathrm{TiO}_{2}$ nanoparticles were gained by calcining the $\mathrm{TiO}_{2}$ xerogel 
at $450^{\circ} \mathrm{C}$ for $3 \mathrm{~h}$ and grinding. The preparation of Sn-doped $\mathrm{TiO}_{2}$ nanoparticles was the same as that of $\mathrm{TiO}_{2}$, except that the water used for the synthesis contained the required amount of tin (IV) chloride.

2.3. Analytical Methods. Powder X-ray diffraction (XRD) was used for identification of crystalline phases and estimation of the crystallite size. The X-ray diffraction (XRD) patterns were recorded on a Siemens/D5000 X-ray diffractometer with $\mathrm{Cu} \mathrm{K} \alpha$ radiation $(\lambda=0.15478 \mathrm{~nm})$. The texture and morphology of the prepared samples were measured by scanning electron microscope (SEM) (Philips XL-30ESM). Transmission electron microscopy (TEM) observation was carried out on Zeiss EM $900-80 \mathrm{keV}$ electron microscopy instrument. The sample for TEM was prepared by dispersing the final powder in ethanol, and the dispersion was then dropped on copper/carbon grid. The nitrogen adsorption and desorption isotherms at $77 \mathrm{~K}$ were measured using Belsorp mini II. The specific surface area and the pore size distribution (average pore diameter and mean pore volume) were measured from the adsorption isotherm using the BrunauerEmmett-Teller (BET) method and from the desorption isotherm using the Barret-Joyner-Halender (BJH) method, respectively. Ultraviolet/visible diffuse reflectance spectra (DRS) were taken on Avaspec-2048 TEC spectrometer. Total organic carbon (TOC) was measured with Shimadzu 5000A TOC analyzer equipped with an autosampler (ASI-5000) and platinum-based catalyst. The carrier gas was synthetic air at the rate of $150 \mathrm{~mL} / \mathrm{min}$. The samples were acidified to $\mathrm{pH}<$ 4 before being sent to TOC analyzer to ensure that inorganic carbon would be released from the solution as $\mathrm{CO}_{2}$.

2.4. Photocatalytic Activity. Mineralization of AMOX under UV light was used as a model reaction to evaluate the photocatalytic activity of prepared samples. Photocatalytic activity measurements were carried out at atmospheric pressure in a batch quartz reactor [24]. Artificial irradiation was provided by $15 \mathrm{~W}$ (UV-C) mercury lamp (Philips, Holland) emitted around $254 \mathrm{~nm}$ positioned parallel to the reactor [25]. In each run, desired concentration of AMOX $\left(20 \mathrm{mg} \mathrm{L}^{-1}\right)$ and $\mathrm{TiO}_{2}$ was fed into the quartz tube reactor and it was allowed to equilibrate for $30 \mathrm{~min}$ in the darkness. The zero time reading was obtained from blank solution kept in the dark. Aliquots of the mixture were taken at periodic intervals during the irradiation, centrifuged for $10 \mathrm{~min}$ at $1000 \mathrm{rpm}$ (Hettich EBA) to remove catalyst particles, and then analyzed for their total organic carbon (TOC) content.

All the concentration profiles can be correlated to irradiation time by the following exponential function with good agreement:

$$
\frac{-d \mathrm{TOC}}{d t}=k_{\mathrm{ap}} \text { TOC. }
$$

Therefore, the photocatalytic mineralization of AMOX is pseudo-first-order reaction, and its kinetics may also be expressed as

$$
\ln \left(\frac{\mathrm{TOC}_{0}}{\mathrm{TOC}}\right)=k_{\mathrm{ap}} t
$$

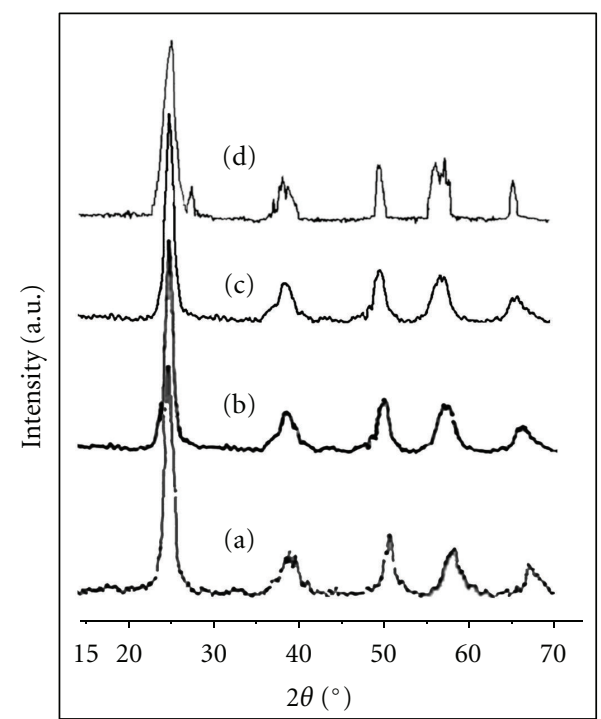

Figure 1: XRD patterns of (a) $\mathrm{TiO}_{2}$, (b) $1 \mathrm{~mol} \% \mathrm{Sn} / \mathrm{TiO}_{2}$, (c) $1.5 \mathrm{~mol} \% \mathrm{Sn} / \mathrm{TiO}_{2}$, (d) $3 \mathrm{~mol} \% \mathrm{Sn} / \mathrm{TiO}_{2}$.

In this equation, $\mathrm{TOC}_{0}$ and $\mathrm{TOC}$ are the antibiotic concentrations $\left(\mathrm{mg} \mathrm{L}^{-1}\right)$ at times 0 and $t$, respectively, and $k_{\mathrm{ap}}$ is the pseudo-first-order rate constant $\left(\mathrm{min}^{-1}\right)$.

\section{Results and Discussion}

\subsection{Characterization of Nanoparticles}

3.1.1. X-Ray Diffraction. Based on the XRD spectra, the crystalline phases could be categorized into two primary components, an anatase $(A)$ and a rutile $(R)$ phase, and represented the intensity of the strongest anatase reflection of (101) plane at $2 \theta=25.3^{\circ} \pm 0.1^{\circ}$, anatase reflection of (200) plane at $2 \theta=48.0^{\circ} \pm 0.1^{\circ}$, and the intensity of the strongest rutile reflection of (110) plane at $2 \theta=27.4^{\circ} \pm 0.1^{\circ}$. Additionally, the anatase phase of $\mathrm{TiO}_{2}$ crystal is a tetragonal system in lattice geometry [26]. The average crystallite size of the particles was calculated according to following Scherrer's equation [27];

$$
D=\frac{k \lambda}{\beta \cos \theta} \text {. }
$$

In this equation, $\lambda$ the $\mathrm{X}$-ray wavelength equal to $0.154 \mathrm{~nm}, k$ is a constant taken as $0.89, \beta$ is the line width at half maximum height, and $\theta$ is the diffracting angle. The phase content of a sample can be calculated by following equation [28]:

$$
\text { Rutile phase } \%=\frac{100}{1+0.08\left(I_{A} / I_{R}\right)},
$$

where $I_{A}$ and $I_{R}$ are integrated intensities of the anatase and rutile peaks, respectively. Figure 1 shows the $\mathrm{X}$-ray diffraction patterns of $\mathrm{TiO}_{2}$ and $1.5 \mathrm{~mol} \% \mathrm{Sn} / \mathrm{TiO}_{2}$ samples. Intensity of the anatase main peak located in $2 \theta=25.5^{\circ}$ indicates a high degree of crystallinity for these nanoparticles. Crystallite 


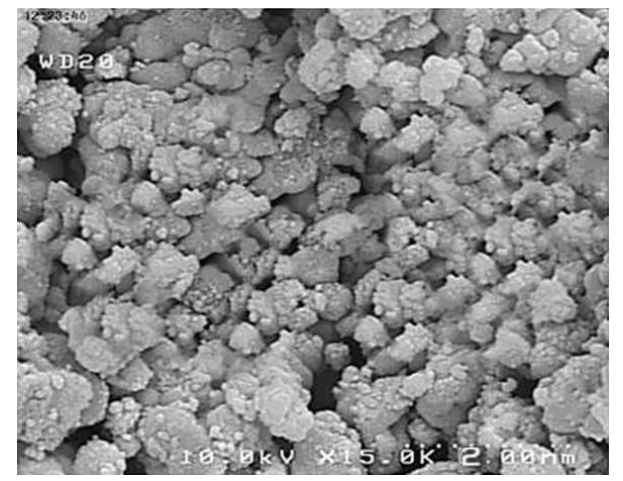

Figure 2: SEM image of $1.5 \mathrm{~mol} \% \mathrm{Sn} / \mathrm{TiO}_{2}$ nanoparticles.

TABle 2: Phase content and crystallite size of prepared nanoparticles.

\begin{tabular}{lcc}
\hline Sample & Phase structure & Crystalline size $(\mathrm{nm})$ \\
\hline $\mathrm{TiO}_{2}$ & $A: 100, R:-$ & $D_{A}: 10, D_{R}:-$ \\
$1 \mathrm{~mol} \% \mathrm{Sn} / \mathrm{TiO}_{2}$ & $A: 100, R:-$ & $D_{A}: 9.1, D_{R}:-$ \\
$1.5 \mathrm{~mol} \% \mathrm{Sn} / \mathrm{TiO}_{2}$ & $A: 100, R:-$ & $D_{A}: 8.4, D_{R}-$ \\
$3 \mathrm{~mol} \% \mathrm{Sn} / \mathrm{TiO}_{2}$ & $A: 89, R: 11$ & $D_{A}: 7, D_{R}: 8.5$ \\
\hline
\end{tabular}

size and amount of each phase nanoparticles have been reported in Table 2 . The crystallite size of titania decreases with increasing doping concentration. This reduction in crystallite size is proposed due to segregation of the dopant cations at the grain boundary which inhibits the grain growth by restricting direct contact of grains. The phase composition varies with the increasing content of Sn. According to the XRD patterns, the pure $\mathrm{TiO}_{2}$ sample constituted pure anatase phase. On the other hand, the sample containing $\mathrm{Sn}$ shows a multiphase composition as the Sn content increases. The $3 \mathrm{~mol} \% \mathrm{Sn}$ sample is composed of crystallites of both anatase and rutile phase. The formation of crystallites of rutile phase at a low calcination temperature is induced by the presence of $\mathrm{Sn}$, as previously reported [29]. Metal may have been finely dispersed, incorporated in the $\mathrm{TiO}_{2}$ crystal structure, or crystals are too small for detection due to a relatively low metal doping [30].

3.1.2. SEM Analysis of $\mathrm{Sn} / \mathrm{TiO}_{2}$ Nanoparticles. The SEM image of $1.5 \mathrm{~mol} \% \mathrm{Sn} / \mathrm{TiO}_{2}$ is shown in Figure 2. Since less particle agglomeration occurred, the large surface area conveys high adsorption abilities of the catalysts. This image shows relatively uniform particles which are coherent together.

3.1.3. TEM Analysis of $\mathrm{Sn} / \mathrm{TiO}_{2}$ Nanoparticles. Figure 3 shows TEM images of $\mathrm{TiO}_{2}$ and $1.5 \mathrm{~mol} \% \mathrm{Sn} / \mathrm{TiO}_{2}$ nanoparticles. It can be seen that the particles exhibit a relatively uniform particle size distribution. The average size of the primary particles estimated from the TEM image is about 7$10 \mathrm{~nm}$, which is in good agreement with that calculated from the XRD pattern using Scherrer equation.
TABLE 3: BET data for $\mathrm{TiO}_{2}$ and $1.5 \mathrm{~mol} \% \mathrm{Sn} / \mathrm{TiO}_{2}$.

\begin{tabular}{lccc}
\hline Sample & $\begin{array}{c}\text { BET surface area } \\
\left(\mathrm{m}^{2} \mathrm{~g}^{-1}\right)\end{array}$ & $\begin{array}{c}\text { Total pore volume } \\
\left(\mathrm{cm}^{3} \mathrm{~g}^{-1}\right)\end{array}$ & $\begin{array}{c}\text { Mean pore } \\
\text { diameter }(\mathrm{nm})\end{array}$ \\
\hline $\mathrm{TiO}_{2}$ & 47.03 & 0.112 & 9.7 \\
$\begin{array}{l}1.5 \mathrm{~mol} \% \\
\mathrm{Sn} / \mathrm{TiO}_{2}\end{array}$ & 80.03 & 0.178 & 8.9 \\
\hline
\end{tabular}

3.1.4. BET Analysis. Figure 4 shows nitrogen adsorptiondesorption isotherms of $\mathrm{TiO}_{2}$ and $1.5 \mathrm{~mol} \% \mathrm{Sn} / \mathrm{TiO}_{2}$ samples. Both samples show the isotherm of type IV. At high relative pressure range from 0.4 to 1 , the isotherm exhibits a hysteresis loop of type $\mathrm{H} 2$ associated with the ink bottle pores, indicating that the powders contain mesopores due to the aggregation of crystallites [31]. The hysteresis loop in the lower relative pressure range $(0.4<P / P 0)$ was related to finer intra-aggregated pores formed between intraagglomerated primary particles, and that in the higher relative pressure range $(0.8<P / P 0<1)$ was associated with larger interaggregated pores produced by interaggregated secondary particles [32]. The porous structure is believed to facilitate the transporting of reactant molecules and products through the interior space due to the interconnected porous networks and favor the harvesting of exciting light due to enlarged surface area and multiple scattering within the porous framework [33].

Figure 5 shows the pore size distribution of $1.5 \mathrm{~mol} \%$ $\mathrm{Sn} / \mathrm{TiO}_{2}$ as estimated according to the $\mathrm{BJH}$ method from the adsorption branch. It can be seen that the diameter range of pores located from 0.97 to $10 \mathrm{~nm}$ and the mean diameter of pores is $8.9 \mathrm{~nm}$. With doping of $\mathrm{Sn}$, the average pore size decreases slightly from 9.7 to $8.9 \mathrm{~nm}$ (Table 1 ). There are two possible factors causing the decrease in average pore size. One is that the aggregation of smaller crystallites forms smaller pores. The other is that some ions of doping probably insert into the pore of pure $\mathrm{TiO}_{2}$, which also causes pore size to become smaller [34]. The specific surface area determined with the BET method is $80.03 \mathrm{~m}^{2} \mathrm{~g}^{-1}$ which is higher than $47.03 \mathrm{~m}^{2} \mathrm{~g}^{-1}$ of $\mathrm{TiO}_{2}$ sample. The enhanced surface area of $1.5 \mathrm{~mol} \% \mathrm{Sn} / \mathrm{TiO}_{2}$ compared to nanosized $\mathrm{TiO}_{2}$ is due to its increase in the mesopore size and mesopore volume [35]. Loganathan et al. [36] have reported that metal doping at a specific concentration can have a favorable effect on the surface area. However, at an excess doping concentration, it could result in the damage of the porous framework, thus negatively affecting the surface area.

The specific surface area, pore volume, and pore size of $\mathrm{TiO}_{2}$ and $1.5 \mathrm{~mol} \% \mathrm{Sn} / \mathrm{TiO}_{2}$ nanoparticles are presented in Table 3. The increase of surface area can be useful in the efficiency of the photocatalytic activity as it implies larger contact surfaces exposed to the reagents [37]. It is accepted in heterogeneous photocatalysis process that higher surface area and pore volume can be useful in the formation of photogenerated electron and hole pairs. Hence, heterogeneous photocatalysis is influenced greatly by the surface area and pore structure [38]. 


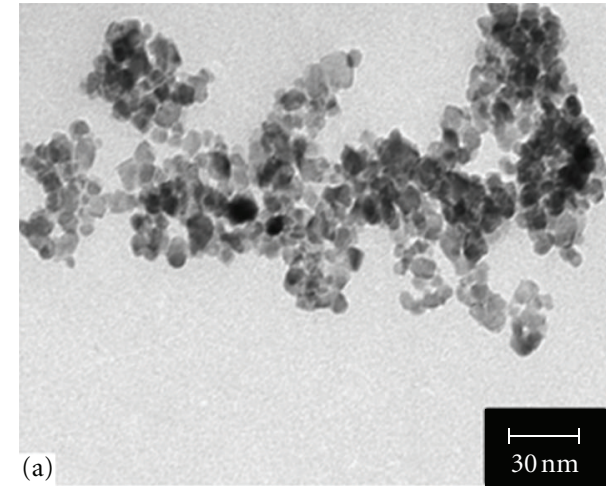

Figure 3: TEM images of (a) $\mathrm{TiO}_{2}$, (b) $1.5 \mathrm{~mol} \% \mathrm{Sn} / \mathrm{TiO}_{2}$ nanoparticles.

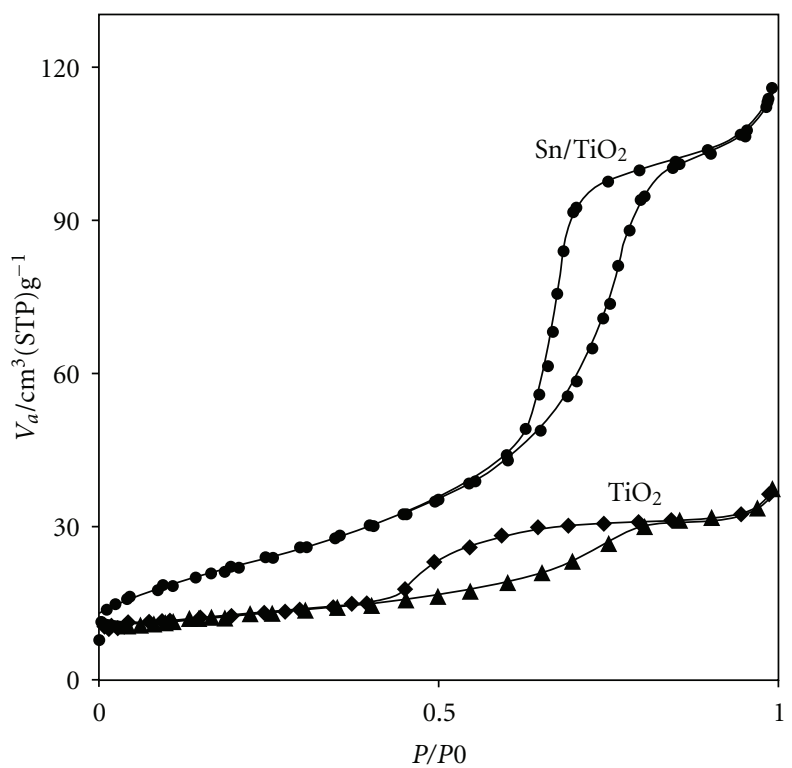

FIgURE 4: Adsorption-desorption isotherms of $\mathrm{TiO}_{2}$ and $1.5 \mathrm{~mol} \%$ $\mathrm{Sn} / \mathrm{TiO}_{2}$.

3.1.5. DRS Analysis. To investigate the optical absorption properties of synthesized samples, diffuse reflectance spectra (DRS) were analyzed. Sn-doping obviously affects light absorption characteristics of $\mathrm{TiO}_{2}$ as shown in Figure 6. The reflectance spectrum of $\mathrm{TiO}_{2}$ nanoparticles show an absorption threshold at $400 \mathrm{~nm}$, while for $\mathrm{Sn} / \mathrm{TiO}_{2}$ samples the absorption threshold is between 390 and $381 \mathrm{~nm}$. The absorbance of $\mathrm{Sn} / \mathrm{TiO}_{2}$ nanoparticles is shifted toward shorter wavelength than $\mathrm{TiO}_{2}$ nanoparticles. In general, blue shift of the absorption onset of Sn-doped nanoparticles is associated with the increase of the carrier concentration blocking the lowest states in the conduction band, well known as the Burstein-Moss effect $[39,40]$. The theory for band-gap widening for polar semiconductors, proposed by Sernelius et al. [41], in order to describe the experimentally found blue shift in $\mathrm{Sn} / \mathrm{TiO}_{2}$ nanoparticles, considers displacement polarization effects and structural disorder as additional factors that affect the shape of the band tails.
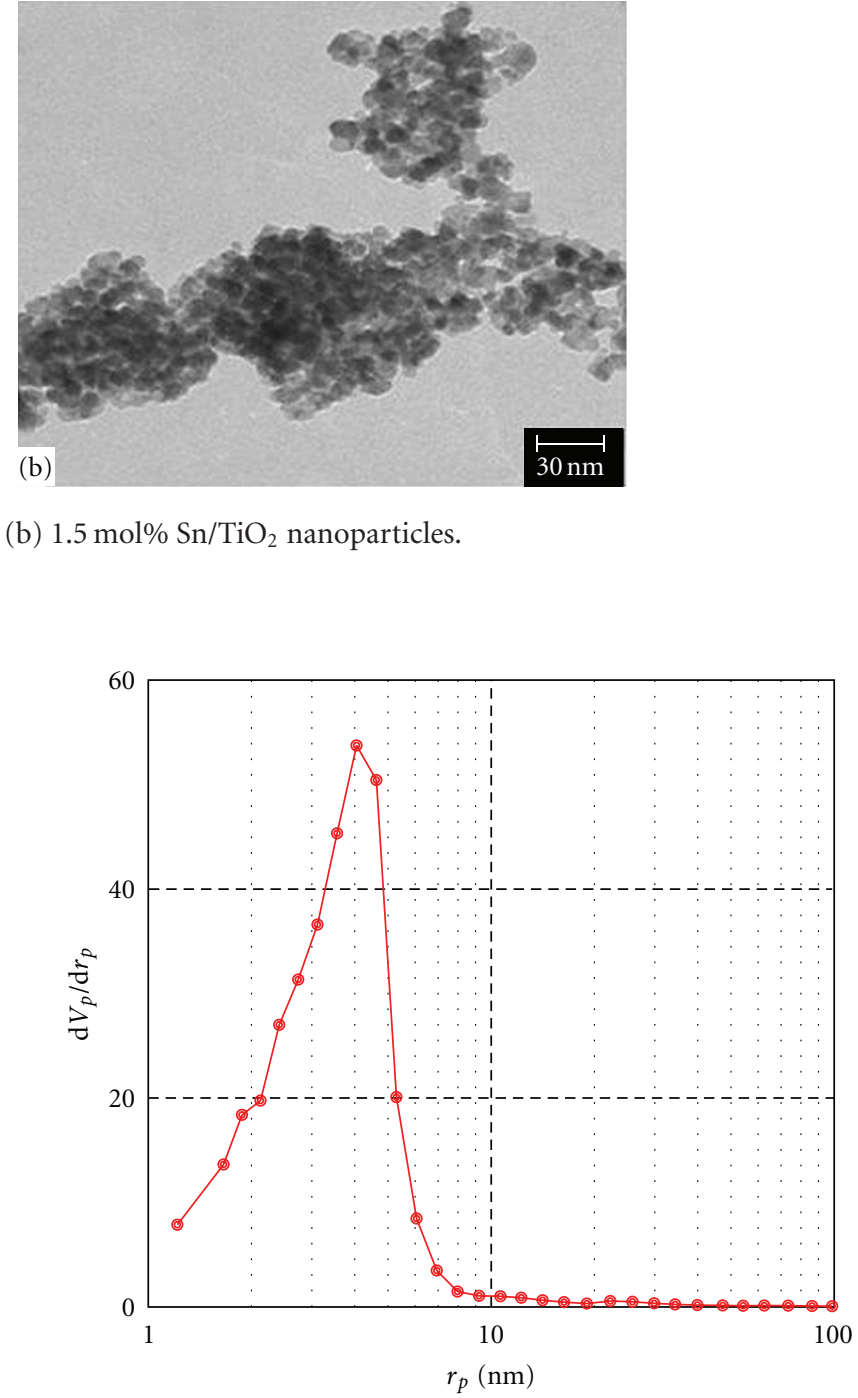

FIgure 5: Pore diameter distribution of $1.5 \mathrm{~mol} \% \mathrm{Sn} / \mathrm{TiO}_{2}$.

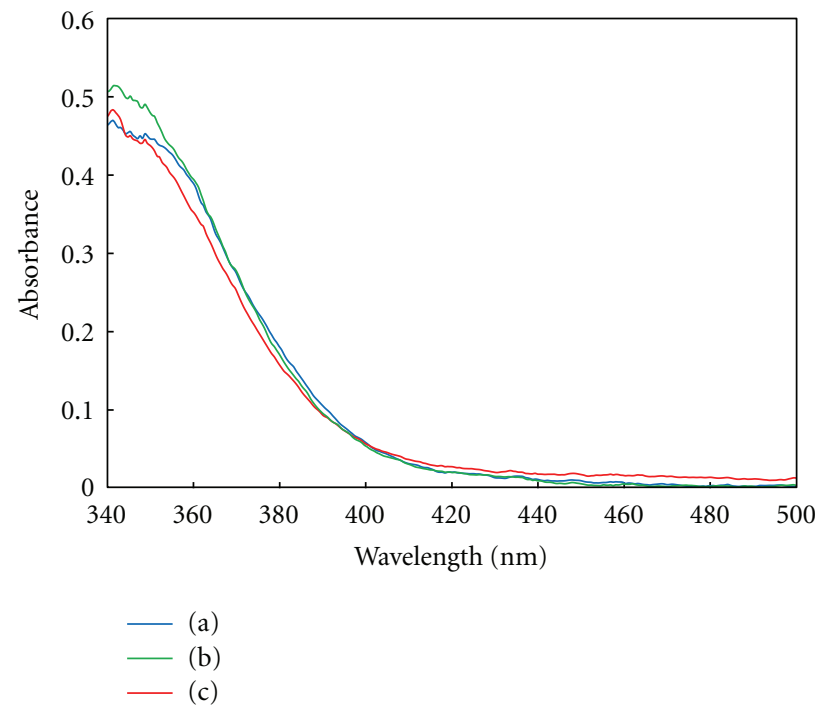

Figure 6: UV-Vis absorption spectra of (a) $\mathrm{TiO}_{2}$, (b) $1 \mathrm{~mol} \%$ $\mathrm{Sn} / \mathrm{TiO}_{2}$, (c) $1.5 \mathrm{~mol} \% \mathrm{Sn} / \mathrm{TiO}_{2}$, (d) $3 \mathrm{~mol} \% \mathrm{Sn} / \mathrm{TiO}_{2}$. 


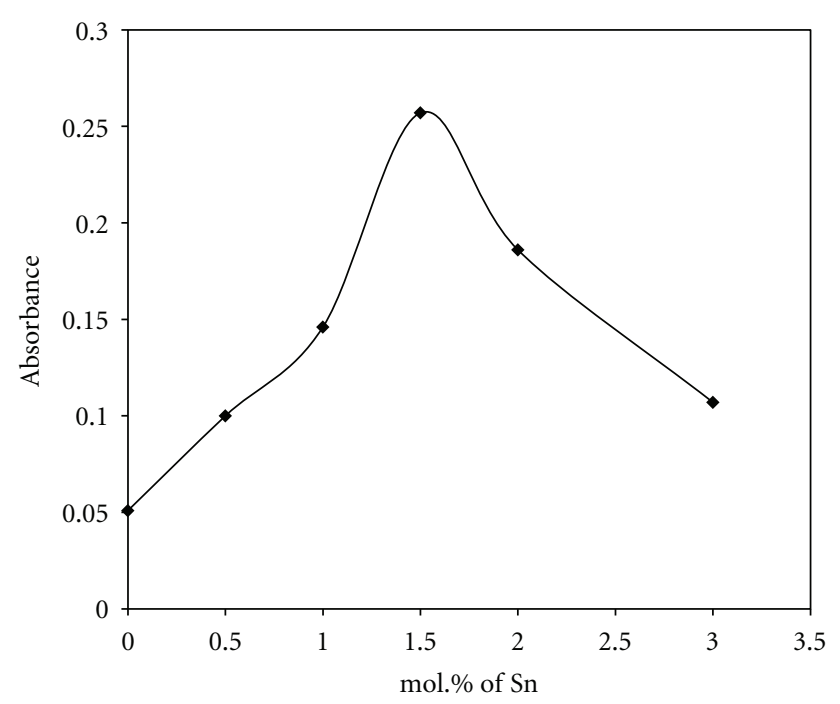

Figure 7: Hydroxyl radical amounts on $\mathrm{Sn} / \mathrm{TiO}_{2}$ nanoparticles with different Sn content.

The direct band-gap energy can be estimated from a plot of $(\alpha h v)^{2}$ versus photon energy $(h v) . \mathrm{Sn} / \mathrm{TiO}_{2}$ nanoparticles show higher band-gap energy than $\mathrm{TiO}_{2}$ nanoparticles. The band gap energy estimated from DRS analysis for $\mathrm{Sn} / \mathrm{TiO}_{2}$ nanoparticles is between 3.17 and $3.25 \mathrm{eV}$, which is higher than $3.1 \mathrm{eV}$ for $\mathrm{TiO}_{2}$. The band gap plays a critical role in deciding the photocatalytic activity of photocatalysts for the reason that it participates in determining the $\mathrm{e}^{-} / \mathrm{h}^{+}$ recombination rate. According to Moss-Burstein theory, in heavily doped $\mathrm{TiO}_{2}$ nanoparticles, the donor electrons occupy states at the bottom of the conduction band. Since the Pauli principal prevents states from being doubly occupied and optical transition is vertical, the valence electrons require extra energy of doped $\mathrm{TiO}_{2}$ to be boarder than that of pure $\mathrm{TiO}_{2}$ nanoparticles [42].

3.1.6. Measurement of Hydroxyl Radical. It is well understood that hydroxyl radical is generated upon proper photon illumination to photocatalyst. The hydroxyl radical is a powerful oxidizing species, having potential oxidation of approximately 2.8 volt (versus $\mathrm{NHE}$ ), which may lead to complete mineralization of pollutants. Generally, the greater the formation rate of ${ }^{*} \mathrm{OH}$ radicals is, the higher separation efficiency of electron-hole pairs is achieved. So, the photocatalytic activity is a positive correlation to the formation rate of $* \mathrm{OH}$ radicals, namely, a faster formation rate of $* \mathrm{OH}$ radicals leads to a higher photo-catalytic activity [43]. The effect of different Sn content on the amount of hydroxyl radical was detected using salicylic acid as a probe molecule [44]. The salicylic acid reacted with the hydroxyl radicals to form 2,3-dihydroxybenzoic acid. After reacting $20 \mathrm{~min}$, the amounts of hydroxyl radicals absorbed by the solution at the wavelength of $510 \mathrm{~nm}$ were measured. A blank experiment was run before adding the photocatalyst. No change is observed in the absorbance, which indicated that there was no photolysis reaction in salicylic acid under UV irradiation.

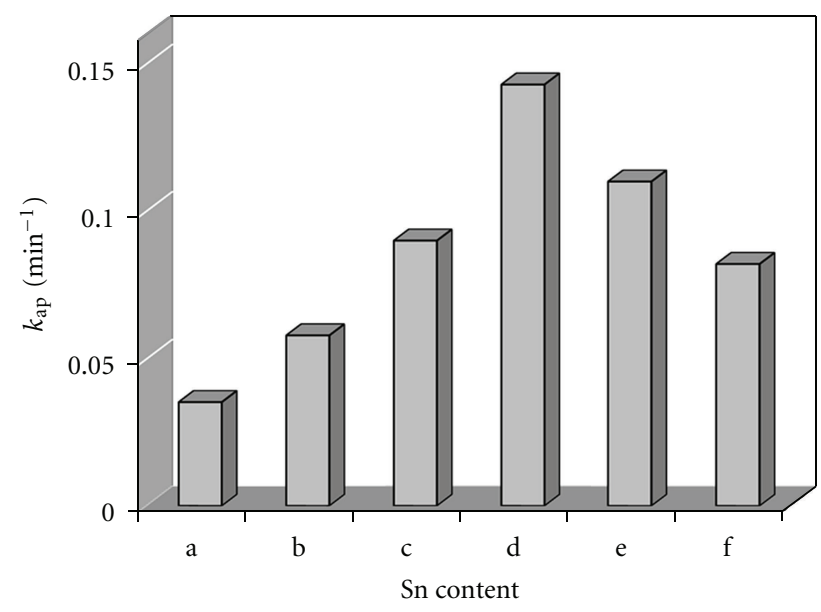

FIGURE 8: Influence of Sn content on the photocatalytic activity of samples under UV irradiation: (a) $0.0 \% \mathrm{Sn} / \mathrm{TiO}_{2}$, (b) $0.5 \mathrm{~mol} \%$ $\mathrm{Sn} / \mathrm{TiO}_{2}$, (c) $1 \mathrm{~mol} \% \mathrm{Sn} / \mathrm{TiO}_{2}$, (d) $1.5 \mathrm{~mol} \% \mathrm{Sn} / \mathrm{TiO}_{2}$, (e) $2 \mathrm{~mol} \%$ $\mathrm{Sn} / \mathrm{TiO}_{2}$ and (f) $3 \mathrm{~mol} \% \mathrm{Sn} / \mathrm{TiO}_{2}$.

Figure 7 shows the hydroxyl radical with different Sn content. The amount of hydroxyl radicals increases as the Sn content increases. The hydroxyl radical of $1.5 \mathrm{~mol} \% \mathrm{Sn} / \mathrm{TiO}_{2}$ is very high, indicating that the sample has a high separation rate of photoinduced carriers. However, the amount of hydroxyl radicals can decrease if the Sn content is too high. The reason is that the amount of photoinduced electrons accumulating instantly at the $\mathrm{SnO}_{2}$ conduction band is too much due to excess $\mathrm{SnO}_{2}$ so that some photoelectrons can indirectly recombine with holes [45]. Therefore, it can be concluded that the separation rate of photoinduced charge carriers can be improved by doping an appropriate amount of Sn.

\subsection{Photocatalytic Activity Studies}

3.2.1. Photocatalytic Mineralization of AMOX Using $\mathrm{Sn} / \mathrm{TiO}_{2}$ Nanoparticles. The results of mineralization of AMOX using $\mathrm{Sn} / \mathrm{TiO}_{2}$ nanoparticles are illustrated in Figure 8. As the irradiation time increased, AMOX degraded into small fragments and subsequently mineralized completely. It could be seen that the photocatalytic activity of $\mathrm{Sn} / \mathrm{TiO}_{2}$ nanoparticles was higher than that of the pure $\mathrm{TiO}_{2}$. Further observation showed that photocatalytic activity gradually increased with increasing content of $\mathrm{Sn}$. The slight enhancement of photocatalytic activity of $0.5 \mathrm{~mol} \% \mathrm{Sn} / \mathrm{TiO}_{2}$ nanoparticles could be assigned to the fact that the excited electrons from the valence band to the conduction band could migrate to Sn nanoparticles and then migrated to $\mathrm{O}_{2}$ molecules adsorbed on the surface of the Sn. Sn produced an Schottky barrier, which facilitated the electron capture [46]. Especially, when the content of Sn increased to $1.5 \mathrm{~mol} \%$, the photocatalytic activity of $\mathrm{Sn} / \mathrm{TiO}_{2}$ nanoparticles significantly increased. The high photo-catalytic activity of $1.5 \mathrm{~mol} \% \mathrm{Sn} / \mathrm{TiO}_{2}$ sample is due to the following several factors.

(i) $\mathrm{TiO}_{2}$ is a photoactive semiconductor that when illuminated with photon energy equal or greater than its 
band gap energy, the following reaction took place on the surface of the photo-catalyst:

$$
\begin{gathered}
\mathrm{TiO}_{2}+h v \longrightarrow \mathrm{TiO}_{2}\left(\mathrm{e}^{-}+\mathrm{h}^{+}\right) \\
\mathrm{h}^{+}+\mathrm{H}_{2} \mathrm{O} \longrightarrow{ }^{*} \mathrm{OH}+\mathrm{H}^{+} \\
\mathrm{h}^{+}+\mathrm{OH}^{-} \longrightarrow{ }^{*} \mathrm{OH} \\
{ }^{*} \mathrm{OH}+\text { antibiotic } \longrightarrow \mathrm{CO}_{2}+\mathrm{H}_{2} \mathrm{O} \\
\mathrm{h}^{+}+\mathrm{e}^{-} \longrightarrow \mathrm{N}+\text { energy. }
\end{gathered}
$$

$\mathrm{SnO}_{2}$ and $\mathrm{TiO}_{2}$ are both wide band gap semiconductors. Although the band gap of $\mathrm{SnO}_{2}(3.8 \mathrm{eV})$ is wider than that of $\mathrm{TiO}_{2}(3.1 \mathrm{~V})$, the Fermi lever of $\mathrm{SnO}_{2}$ is lower than that of $\mathrm{TiO}_{2}$. It means that the photo-generated electrons may easily transfer from $\mathrm{TiO}_{2}$ to $\mathrm{SnO}_{2}$, but not to recombine with the photo-generated holes on the surface of $\mathrm{TiO}_{2}$ immediately. Consequently, more and more holes are present on the surface and take part in the reactions of oxidizing $\mathrm{OH}^{-}$and $\mathrm{H}_{2} \mathrm{O}$ into hydroxyl radicals. Hydroxyl radicals would be finally responsible for the degradation of pollutants into $\mathrm{H}_{2} \mathrm{O}$ and $\mathrm{CO}_{2}[47,48]$. Furthermore, photo-induced electrons easily transfer from $\mathrm{TiO}_{2}$ to $\mathrm{SnO}_{2}$ due to their potential difference of conduction band. According to [49], the conduction band $(\mathrm{CB})$ edges of $\mathrm{TiO}_{2}$ and $\mathrm{SnO}_{2}$ are situated at -0.34 and $+0.07 \mathrm{~V}$ versus normal hydrogen electrode (NHE) at $\mathrm{pH}$ 7. Thus, electron can easily flow into $\mathrm{SnO}_{2}$, which has a more positive conduction band. This results into the decrease in the chance of recombination of photoinduced carriers so that the separation rate of photoinduced electron-hole pairs can improve, that is, the amount of hydroxyl radicals can increase. The amounts of hydroxyl radicals and the efficient charge separation directly influenced the photocatalytic activity [45]. As can be seen in Figure 8 , the photocatalytic activity of $1.5 \mathrm{~mol} \% \mathrm{Sn} / \mathrm{TiO}_{2}$ is very high, indicating that the sample has a high separation rate of photoinduced carriers.

(ii) A small amount of metal ions can act as a photogenerated hole and a photo-generated electron trap and inhibit the hole-electron recombination:

$$
\begin{aligned}
& \mathrm{M}^{n+}+e_{C B}^{-} \rightarrow \mathrm{M}^{(n-1)+} \quad \text { (electron trap) } \\
& \mathrm{M}^{n+}+\mathrm{h}_{\mathrm{VB}}{ }^{+} \rightarrow \mathrm{M}^{(n+1)+} \quad \text { (hole trap). }
\end{aligned}
$$

The trapped electron may thus be readily transferred to oxygen molecule to form a superoxide radical anion $\left(\mathrm{O}_{2}{ }^{\circ-}\right)$. In addition, the trapped hole can be easily transferred to hydroxyl anion adsorbed on the surface forming hydroxyl radical $\left(\mathrm{OH}^{*}\right)$, or it can also be transferred to adsorbed dye molecule to form a dye radical [50].

$\mathrm{Sn} / \mathrm{TiO}_{2}$ nanoparticles show higher band-gap energy than $\mathrm{TiO}_{2}$ nanoparticles, which not only suppressed the electron-hole recombination but also generated more $* \mathrm{OH}$ radicals [35]. (iii) The superior degradation efficiency of $\mathrm{Sn} / \mathrm{TiO}_{2}$ nanoparticles could be attributed to a larger surface area compared to another photocatalyst. A large surface area may be an important factor in certain photocatalytic mineralization reactions, as a large amount of adsorbed organic molecules promotes the reaction rate [51].

(iv) Particle size is another important parameter influencing photocatalytic efficiency, since the electron-hole recombination rate may depend on the particle size. It is well known that in the nanometer-size range, physical and chemical properties of semiconductors are modified (compared with bulk). Small variations in particle diameters lead to great modifications in the surface/bulk ratio, thus influencing the recombination rates of volume and surface electrons and holes [52].

Moreover, a decrease in the activity is expected when the content of $\mathrm{Sn}$ becomes too large. The detrimental effect of tin on $\mathrm{TiO}_{2}$ photoactivity has several reasons.

(v) The amount of photoinduced electrons accumulating instantly at the $\mathrm{SnO}_{2}$ conduction band is too much due to excess $\mathrm{SnO}_{2}$ so that some photoelectrons can indirectly recombine with holes [45].

(vi) An excess amount of Sn dopant can produce the recombination center of photoinduced electron and hole pairs. Recombination of $\mathrm{e}^{-}-\mathrm{h}^{+}$pairs reduces the rate of photocatalytic mineralization [53].

(vii) Excessive coverage of $\mathrm{TiO}_{2}$ catalyst limits the amount of light reaching to the $\mathrm{TiO}_{2}$ surface, reducing the number of photogenerated $\mathrm{e}^{-}-\mathrm{h}^{+}$pairs and lowering consequently the $\mathrm{TiO}_{2}$ photoactivity [54].

(viii) Doped metal may occupy the active sites on the $\mathrm{TiO}_{2}$ surface for the desired photocatalytic reactions causing the $\mathrm{TiO}_{2}$ to lose its activity [55].

(ix) The probability of the hole capture is increased by the large number of tin particles at high tin dopings, which decrease the probability of holes reacting with adsorbed species at the $\mathrm{TiO}_{2}$ surface [56].

Based on the results, the optimum content of Sndoped $\mathrm{TiO}_{2}$ for treatment of AMOX in aqueous solution is $1.5 \mathrm{~mol} \%$.

3.2.2. Effect of the Amount of $\mathrm{Sn} / \mathrm{TiO}_{2}$ Nanoparticles. Photocatalytic mineralization of AMOX may depend on the catalyst amount. In order to investigate the effect of catalyst amount, experiments were carried out by varying the amount of photocatalyst from 100 to $600 \mathrm{mg} \mathrm{L}^{-1}$, and the mineralization profile is shown in Figure 9. The rate of reaction increases with the increase of photocatalyst up to $400 \mathrm{mg} \mathrm{L}^{-1}$ and a further increase leads to a decrease in the antibiotic mineralization. This observation can be explained in terms of availability of active sites on the catalyst surface and the penetration of UV light into the suspension. The total active surface area increases with increasing catalyst dosage [57]. The reasons for decrease in mineralization rate were aggregation of $\mathrm{Sn} / \mathrm{TiO}_{2}$ nanoparticles at high concentration causing a decrease in the number of surface active sites and an increase in the opacity and light scattering of $\mathrm{Sn} / \mathrm{TiO}_{2}$ nanoparticles at high concentration. This tends to 


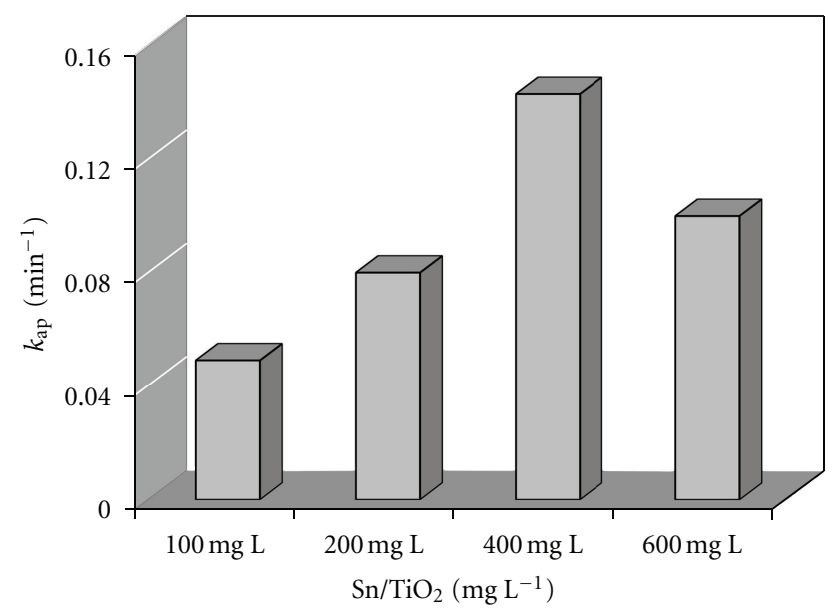

FIgUre 9: Effect of $\mathrm{Sn} / \mathrm{TiO}_{2}$ amount on AMOX mineralization.

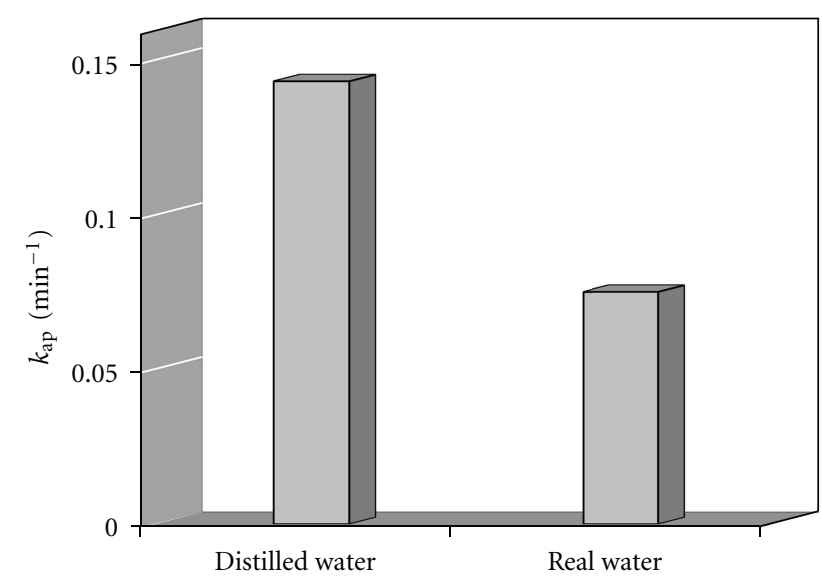

Figure 10: Investigation of the efficiency of $1.5 \mathrm{~mol} \% \mathrm{Sn} / \mathrm{TiO}_{2}$ in mineralization of AMOX from real water.

decrease the passage of irradiation through the sample [58]. The catalyst concentration above which conversion levels off depends on several factors (e.g., reactor geometry, operating conditions, wavelength, and intensity of light source) and corresponds to the point where all catalyst particles, that is, all the surface exposed, are fully illuminated [4]. In this study, the optimum concentration at which all subsequent experiments were conducted was about $400 \mathrm{mg} \mathrm{L}^{-1}$.

3.2.3. Treatment of Real Water Containing AMX. In order to investigate the efficiency of $\mathrm{Sn} / \mathrm{TiO}_{2}$ nanoparticles in mineralization of AMOX in the real water, $20 \mathrm{mg} \mathrm{L}^{-1}$ of antibiotic was added into a real water sample (carbonate hardness: $94 \mathrm{mg} \mathrm{L}^{-1} \mathrm{CaCO}_{3}$, sulphate concentration: $175.1 \mathrm{mg} \mathrm{L}^{-1} \mathrm{SO}_{4}{ }^{2-}$ ) that was obtained from an irrigation well in Tabriz, Iran. Results in Figure 10 show the effect of presence of common anions such as sulphate, carbonate, and bicarbonate on the mineralization of AMX. It is clear from this figure that, in presence of $\mathrm{SO}_{4}{ }^{2-}, \mathrm{HCO}_{3}{ }^{-}$, and $\mathrm{CO}_{3}{ }^{2-}$, the percent of mineralization decreases. This inhibition is

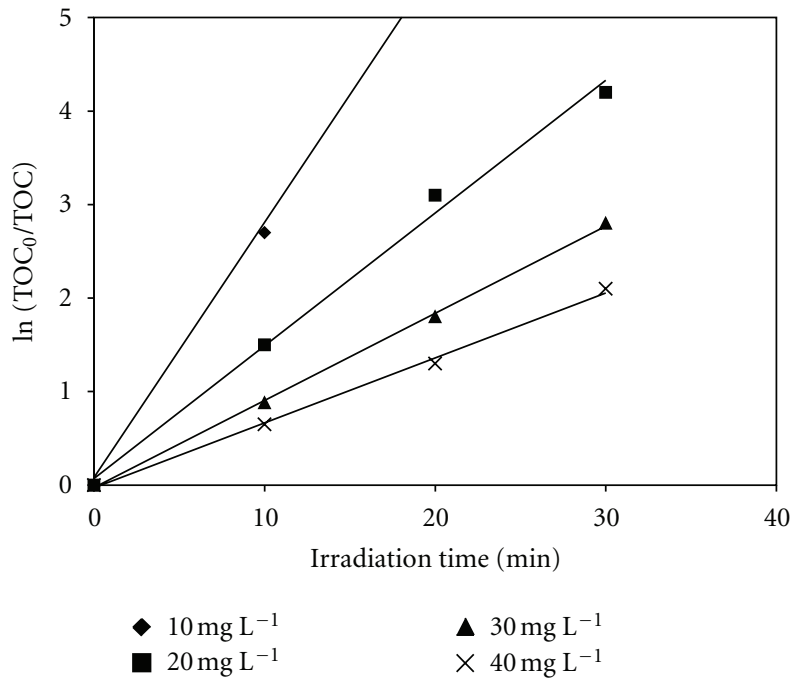

FIGURE 11: Determination of the pseudo-first-order kinetic rate constants, $k_{\mathrm{ap}}$.

TABle 4: Pseudo-first-order kinetic rate constants in photocatalytic experiments with different initial concentration of AMOX.

\begin{tabular}{lcccc}
\hline $\begin{array}{l}{\left[\mathrm{Sn} / \mathrm{TiO}_{2}\right]_{0}} \\
\left(\mathrm{mg} \mathrm{L}^{-1}\right)\end{array}$ & $\begin{array}{c}{[\mathrm{AMOX}]_{0}} \\
\left(\mathrm{mg} \mathrm{L}^{-1}\right)\end{array}$ & $k_{\mathrm{ap}}\left(\mathrm{min}^{-1}\right)$ & $1 / k_{\mathrm{ap}}(\mathrm{min})$ & $r^{2}$ \\
\hline 400 & 40 & 0.068 & 14.5 & 0.997 \\
400 & 30 & 0.09 & 11.1 & 0.999 \\
400 & 20 & 0.143 & 6.95 & 0.994 \\
400 & 10 & 0.25 & 3.98 & 0.991 \\
\hline
\end{tabular}

undoubtedly due to their ability to act as hydroxyl radical's scavengers by the following reactions [59]:

$$
\begin{gathered}
\mathrm{SO}_{4}{ }^{2-}+{ }^{*} \mathrm{OH} \longrightarrow \mathrm{SO}_{4}{ }^{--}+\mathrm{OH}^{-} \\
\mathrm{HCO}_{3}{ }^{-}+{ }^{*} \mathrm{OH} \longrightarrow \mathrm{CO}_{3}{ }^{--}+\mathrm{H}_{2} \mathrm{O} \\
\mathrm{CO}_{3}{ }^{2-}+{ }^{*} \mathrm{OH} \longrightarrow \mathrm{CO}_{3}{ }^{--}+\mathrm{OH}^{-} .
\end{gathered}
$$

These ions may also block the active sites on the $\mathrm{Sn} / \mathrm{TiO}{ }_{2}$ surface thus deactivating the catalysts towards AMOX and intermediate molecules. Although the generated radical anions have been shown to be an oxidant itself, but its oxidation potential is less than that of the hydroxyl radicals.

\subsubsection{Effect of the Initial AMOX Concentration in the} Photocatalytic Reaction. The effect of varying AMOX initial concentration was studied in the range of $10-40 \mathrm{mg} \mathrm{L}^{-1}$. Figure 11 shows a plot of $\ln \left(\mathrm{TOC}_{0} / \mathrm{TOC}\right)$ versus time for all the experiments with different initial concentration of AMOX.

By applying a least square regression analysis, the values of $k_{\text {ap }}$ have been obtained. The results are shown in Figure 12.

Table 4 reports the values of $k_{\text {ap }}$ resulting from plot of $\ln \left([\mathrm{TOC}]_{0} /[\mathrm{TOC}]\right)$ versus "Time," which decreases as 


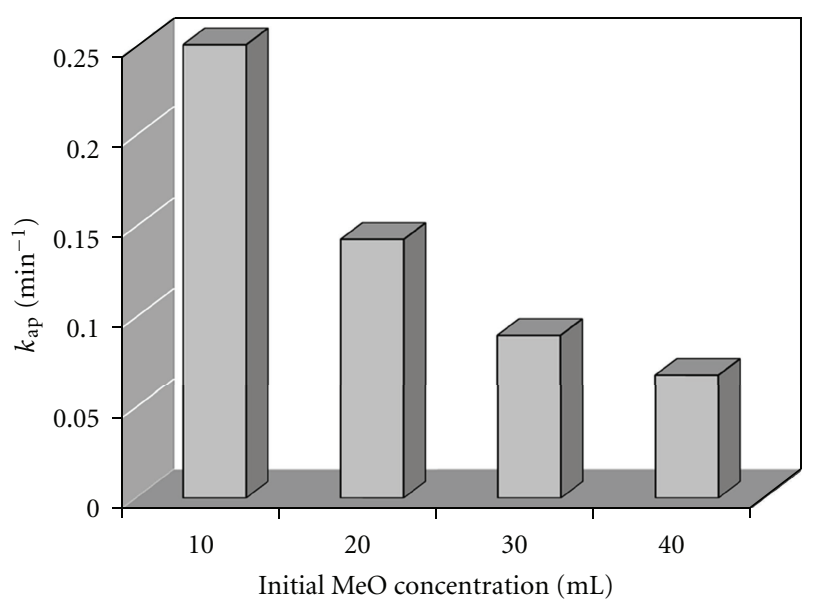

FIGURE 12: Effect of initial AMOX concentration in the photocatalytic reaction.

the initial reactant concentration increases. The presumed reason is that when the initial concentration of antibiotic is increased, more and more antibiotic molecules are adsorbed on the surface of $\mathrm{Sn} / \mathrm{TiO}_{2}$ nanoparticles. The large amount of adsorbed antibiotic is thought to have an inhibitive effect on the reaction of antibiotic molecules with photogenerated holes or hydroxyl radicals, because of the lack of any direct contact between them. This was attributed to the rise of internal optical density, which caused the solution to became impermeable to UV light [60]. Once the concentration of antibiotic is increased, it also causes the antibiotic molecules to absorb light and the photons never reach the photocatalyst surface, and thus the photocatalytic mineralization efficiency decreases $[61,62]$.

Several reports have established that the heterogeneous photo-oxidation rate fits well to the classic LangmuirHinshelwood (L-H) mechanism [63] which in terms of mineralization kinetics can be described as follows:

$$
\begin{gathered}
r=\frac{k_{c} k_{\mathrm{AMOX}}(\mathrm{TOC})}{1+k_{\mathrm{AMOX}}\left(\mathrm{TOC}_{0}\right)}, \\
\frac{1}{k_{\mathrm{ap}}}=\frac{1}{k_{\mathrm{c}} k_{\mathrm{AMOX}}}+\frac{\mathrm{TOC}_{0}}{k_{\mathrm{C}}},
\end{gathered}
$$

where $k_{\mathrm{AMOX}}$ and $k_{\mathrm{c}}$ are the Langmuir-Hinshelwood adsorption equilibrium constant and rate constant of surface reaction, respectively. Using the data from photocatalytic experiments with different initial AMOX concentrations, the values of $k_{\mathrm{AMOX}}$ and $k_{\mathrm{c}}$ can be calculated using the linearized equation by plotting $1 / k_{\text {obs }}$ versus $[\mathrm{TOC}]_{0}$. As can be seen in Figure 13, a straight line fitted the experimental data reasonably well (the coefficient of linear regression, $r$, was 0.994), thus indicating that photocatalytic mineralization of ERM most probably follows Langmuir-Hinshelwood kinetics. From the slope of the straight line, $k_{\mathrm{c}}$ was computed equal to $1.86 \mathrm{mg} \mathrm{L}^{-1} \mathrm{~min}^{-1}$, while from the intercept, $k_{\mathrm{AMOX}}$ was $0.56\left(\mathrm{mg} \mathrm{L}^{-1}\right)^{-1}$. Yurdakal and his coworkers reported Langmuir-Hinshelwood equation constants for mineralization of Gemfibrozil (GEM) drug in the presence of two

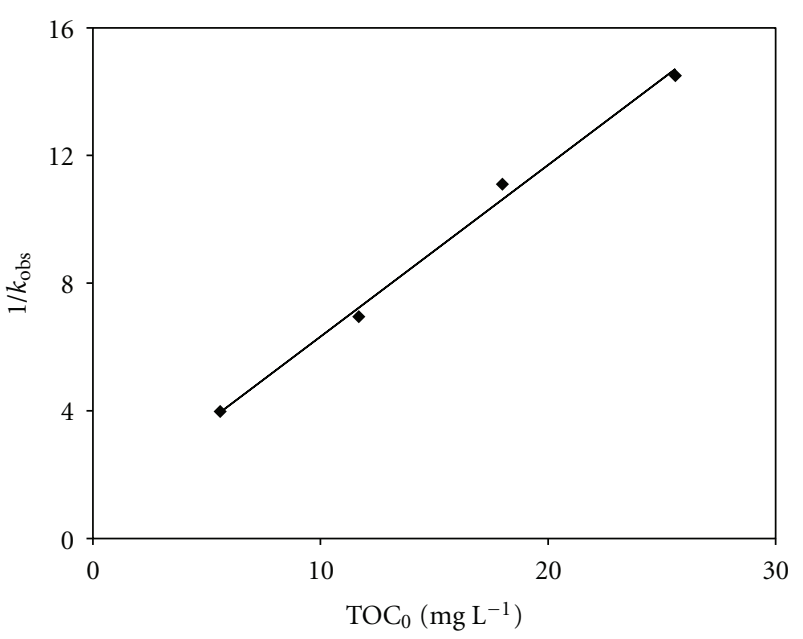

FIGURE 13: Determination of the adsorption equilibrium constant, $k_{\mathrm{AMOX}}$, and the second order rate constant, $k_{\mathrm{c}}$, for the Langmuir-Hinshelwood kinetic model.

commercial polycrystalline $\mathrm{TiO}_{2}$ powders (Degussa P25 and Merck). The values of $k_{\mathrm{c}}$ are $1.91 \times 10^{-8}$ and $6.78 \times$ $10^{-9} \mathrm{~mol} \mathrm{~m}^{-2} \mathrm{~s}^{-1}$ and those of $K_{\mathrm{GEM}} 5.11 \times 10^{3}$ and $1.07 \times$ $10^{5} \mathrm{M}^{-1}$ for Degussa P25 and Merck, respectively [3].

\section{Conclusions}

$\mathrm{TiO}_{2}$ and $\mathrm{Sn} / \mathrm{TiO}_{2}$ nanoparticles could be prepared by sol-gel method using titanium n-butoxide and tin (IV) chloride as precursors. The XRD results showed that the crystallite size greatly decreased due to Sn-doping but an increase in surface area, pore volume, and band gap energy was observed. Nitrogen adsorption-desorption isotherms showed that the adsorption ability was enhanced owing to Sn-doping. The absorbance of $\mathrm{Sn} / \mathrm{TiO}_{2}$ nanoparticles was shifted toward shorter wavelength than $\mathrm{TiO}_{2}$ nanoparticles. The effect of $\mathrm{Sn}$ dopant on the photoinduced charge property was estimated by measuring hydroxyl radicals using salicylic acid as probe molecule. The photocatalytic efficiency for AMOX decomposition was remarkably enhanced owing to Sn-doping, and $1.5 \mathrm{~mol} \% \mathrm{Sn} / \mathrm{TiO}_{2}$ sample had the highest photocatalytic activity due to increase in the generated hydroxyl radicals, band gap energy, specific surface area, and decrease in the crystal size. Langmuir-Hinshelwood kinetic model provided a good fit to the photocatalytic mineralization of AMOX, used in this study. This study confirms the potentialities of heterogeneous photocatalysis to decontaminate wastewaters containing organic pollutants.

\section{References}

[1] J. Ziemianska, E. Adamek, A. Sobszak, I. Lipska, A. Makowaski, and W. Baran, "The study of photocatalytic degradation of sulfonamides applied to minicipal wastewater," Physicochemical Problems of Mineral Processing, vol. 45, pp. 127-140, 2010.

[2] A. Paola, M. Addamo, V. Augugliaro et al., "Photodegradation of lincomycin in aqueous solution," International Journal of Photoenergy, vol. 2006, Article ID 47418, 6 pages, 2006. 
[3] S. Yurdakal, V. Loddo, V. Augugliaro, H. Berber, G. Palmisano, and L. Palmisano, "Photodegradation of pharmaceutical drugs in aqueous $\mathrm{TiO}_{2}$ suspensions: mechanism and kinetics," Catalysis Today, vol. 129, no. 1-2, pp. 9-15, 2007.

[4] N. P. Xekoukoulotakis, N. Xinidis, M. Chroni et al., "UV$\mathrm{A} / \mathrm{TiO}_{2}$ photocatalytic decomposition of erythromycin in water: factors affecting mineralization and antibiotic activity," Catalysis Today, vol. 151, no. 1-2, pp. 29-33, 2010.

[5] D. W. Kolpin, W. E. T. Furlong, M. T. Meyer et al., "Pharmaceuticals, hormones, and other organic wastewater contaminants in U.S. streams, 1999-2000: a national reconnaissance," Environmental Science and Technology, vol. 36, no. 6, pp. 12021211, 2002.

[6] R. A. Palominos, A. Mora, M. A. Mondaca, M. Perez-Moya, and H. D. Mansilla, "Oxolinic acid photo-oxidation using immobilized $\mathrm{TiO}_{2}$," Journal of Hazardous Materials, vol. 158, no. 2-3, pp. 460-464, 2008.

[7] A. J. Watkinson, E. J. Murby, and S. D. Costanzo, "Removal of antibiotics in conventional and advanced wastewater treatment: implications for environmental discharge and wastewater recycling," Water Research, vol. 41, no. 18, pp. 4164-4176, 2007.

[8] C. Reyes, J. Fernández, J. Freer et al., "Degradation and inactivation of tetracycline by $\mathrm{TiO}_{2}$ photocatalysis," Journal of Photochemistry and Photobiology A, vol. 184, no. 1-2, pp. 141146, 2006.

[9] X. Chen and S. S. Mao, "Titanium dioxide nanomaterials: synthesis, properties, modifications and applications," Chemical Reviews, vol. 107, no. 7, pp. 2891-2995, 2007.

[10] Y. Xie and C. Yuan, "Characterization and photocatalysis of $\mathrm{Eu}^{3+}-\mathrm{TiO}_{2}$ sol in the hydrosol reaction system," Materials Research Bulletin, vol. 39, no. 4-5, pp. 533-543, 2004.

[11] H. G. Yu, J. G. Yu, S. W. Liu, and S. Mann, "Templatefree hydrothermal synthesis of $\mathrm{CuO} / \mathrm{Cu}_{2} \mathrm{O}$ composite hollow microspheres," Chemistry of Materials, vol. 19, no. 17, pp. 4327-4334, 2007.

[12] W. Y. Choi, A. Termin, and M. R. Hoffmann, "The role of metal ion dopants in quantum-sized $\mathrm{TiO}_{2}$ : correlation between photoreactivity and charge carrier recombination dynamics," Journal of Physical Chemistry, vol. 98, no. 51, pp. 13669-13679, 1994.

[13] C. Chen, Z. Wang, S. Ruan, B. Zou, M. Zhao, and F. Wu, "Photocatalytic degradation of C.I. Acid Orange 52 in the presence of $\mathrm{Zn}$-doped $\mathrm{TiO}_{2}$ prepared by a stearic acid gel method," Dyes and Pigments, vol. 77, no. 1, pp. 204-209, 2008.

[14] G. Sivalingam, K. Nagaveni, M. S. Hegde, and G. Madras, "Photocatalytic degradation of various dyes by combustion synthesized nano anatase $\mathrm{TiO}_{2}$," Applied Catalysis B, vol. 45, no. 1, pp. 23-38, 2003.

[15] C. A. Castro, A. Jurado, D. Sissa, and S. A. Giraldo, "Performance of $\mathrm{Ag}-\mathrm{TiO}_{2}$ photocatalysts towards the photocatalytic disinfection of water under interior-lighting and solar-simulated light irradiations," International Journal of Photoenergy, vol. 2012, Article ID 261045, 10 pages, 2012.

[16] L. Jia, C. Wu, Y. Li et al., "Enhanced visible-light photocatalytic activity of anatase $\mathrm{TiO}_{2}$ through $\mathrm{N}$ and $\mathrm{S}$ codoping," Applied Physics Letters, vol. 98, Article ID 211903, 3 pages, 2011.

[17] X. Li, J. Lu, Y. Dai, M. Guo, and B. Huang, "The synthetic effects of iron with sulfur and fluorine on photoabsorption and photocatalytic performance in codoped $\mathrm{TiO}_{2}$," International Journal of Photoenergy, vol. 2012, Article ID 203529, 7 pages, 2012.

[18] R. A. Palominos, M. A. Mondaca, A. Giraldo, G. Peñuela, M. Pérez-Moya, and H. D. Mansilla, "Photocatalytic oxidation of the antibiotic tetracycline on $\mathrm{TiO}_{2}$ and $\mathrm{ZnO}$ suspensions," Catalysis Today, vol. 144, no. 1-2, pp. 100-105, 2009.

[19] L. K. Ge, J. W. Chen, S. Y. Zhang, X. Y. Cai, Z. Wang, and C. L. Wang, "Photodegradation of fluoroquinolone antibiotic gatifloxacin in aqueous solutions," Chinese Science Bulletin, vol. 55, no. 15, pp. 1495-1500, 2010.

[20] R. A. Palominos, A. Mora, M. A. Mondaca, M. Pérez-Moya, and H. D. Mansilla, "Oxolinic acid photo-oxidation using immobilized $\mathrm{TiO}_{2}$," Journal of Hazardous Materials, vol. 158, no. 2-3, pp. 460-464, 2008.

[21] M. N. Abellán, B. Bayarri, J. Gimenez, and J. Costa, "Photocatalytic degradation of sulfamethoxazole in aqueous suspension of $\mathrm{TiO}_{2}$," Applied Catalysis B, vol. 74, no. 3-4, pp. 233-241, 2007.

[22] Y. Bessekhouad, D. Robert, and J. V. Weber, "Synthesis of photocatalytic $\mathrm{TiO}_{2}$ nanoparticles: optimization of the preparation conditions," Journal of Photochemistry and Photobiology A, vol. 157, no. 1, pp. 47-53, 2003.

[23] M. A. Behnajady, H. Eskandarloo, N. Modirshahla, and M. Shokri, "Investigation of the effect of sol-gel synthesis variables on structural and photocatalytic properties of $\mathrm{TiO}_{2}$ nanoparticles," Desalination, vol. 278, no. 1-3, pp. 10-17, 2011.

[24] N. Modirshahla, A. Hassani, M. A. Behnajady, and R. Rahbarfam, "Effect of operational parameters on decolorization of Acid Yellow 23 from wastewater by UV irradiation using $\mathrm{ZnO}$ and $\mathrm{ZnO} / \mathrm{SnO}_{2}$ photocatalysts," Desalination, vol. 271, no. 13, pp. 187-192, 2011.

[25] J. Li, J. Xu, W. L. Dai, H. Li, and K. Fan, "Direct hydro-alcohol thermal synthesis of special core-shell structured Fe-doped titania microspheres with extended visible light response and enhanced photoactivity," Applied Catalysis B, vol. 85, no. 3-4, pp. 162-170, 2009.

[26] T. L. Su, C. S. Chiou, and H. W. Chen, "Preparation, photocatalytic activity, and recovery of magnetic photocatalyst for decomposition of benzoic acid," International Journal of Photoenergy, vol. 2012, Article ID 909678, 8 pages, 2012.

[27] M. Hamadanian, A. Reisi-Vanani, and A. Majedi, "Sol-gel preparation and characterization of $\mathrm{Co} / \mathrm{TiO}_{2}$ nanoparticles: application to the degradation of methyl orange," Journal of the Iranian Chemical Society, vol. 7, supplement 1, pp. S52S58, 2010.

[28] R. A. Spurr and H. Myers, "Quantitative analysis of anataserutile mixtures with an X-ray diffractometer," Analytical Chemistry, vol. 29, no. 5, pp. 760-762, 1957.

[29] F. Fresno, J. M. Coronado, D. Tudela, and J. Soria, "Influence of the structural characteristics of $\mathrm{Ti}_{--x} \mathrm{Sn}_{x} \mathrm{O}_{2}$ nanoparticles on their photocatalytic activity for the elimination of methylcyclohexane vapors," Applied Catalysis B, vol. 55, no. 3, pp. 159167,2005

[30] C. R. Estrellan, C. Salim, and H. Hinode, "Photocatalytic decomposition of perfluorooctanoic acid by iron and niobium co-doped titanium dioxide," Journal of Hazardous Materials, vol. 179, no. 1-3, pp. 79-83, 2010.

[31] J. G. Yu, T. T. Ma, and S. W. Liu, "Enhanced photocatalytic activity of mesoporous $\mathrm{TiO}_{2}$ aggregates by embedding carbon nanotubes as electron-transfer channel," Physical Chemistry Chemical Physics, vol. 13, no. 8, pp. 3491-3501, 2011.

[32] J. G. Yu, S. Liu, and H. Yu, "Microstructures and photoactivity of mesoporous anatase hollow microspheres fabricated by fluoride-mediated self-transformation," Journal of Catalysis, vol. 249, no. 1, pp. 59-66, 2007.

[33] P. Madhusudan, J. Ran, J. Zhang, J. Yu, and G. Liu, "Novel urea assisted hydrothermal synthesis of hierarchical 
$\mathrm{BiVO}_{4} / \mathrm{Bi}_{2} \mathrm{O}_{2} \mathrm{CO}_{3}$ nanocomposites with enhanced visible-light photocatalytic activity," Applied Catalysis B, vol. 110, pp. 286295, 2011.

[34] S. Rahimnejad, S. R. Setayesh, and M. R. Gholami, "A credible role of copper oxide on structure of nanocrystalline mesoporous titanium dioxide," Journal of the Iranian Chemical Society, vol. 5, no. 3, pp. 367-374, 2008.

[35] L. Kumaresan, M. Mahalakshmi, M. Palanichamy, and V. Murugesan, "Synthesis, characterization, and photocatalytic activity of $\mathrm{Sr}^{2+}$ doped $\mathrm{TiO}_{2}$ nanoplates," Industrial and Engineering Chemistry Research, vol. 49, no. 4, pp. 1480-1485, 2010.

[36] K. Loganathan, P. Bommusamy, P. Muthaiahpillai, and M. Velayutham, "The syntheses, characterizations, and photocatalytic activities of silver, platinum, and gold doped $\mathrm{TiO}_{2}$ nanoparticles," Environmental Engineering Research, vol. 16, no. 2, pp. 81-90, 2011.

[37] Y. Kotani, T. Matoda, A. Matsuda, T. Kogure, M. Tatsumisago, and T. Minami, "Anatase nanocrystal-dispersed thin films via sol-gel process with hot water treatment: effects of poly(ethylene glycol) addition on photocatalytic activities of the films," Journal of Materials Chemistry, vol. 11, no. 8, pp. 2045-2048, 2001.

[38] J. Li, J. Xu, W. L. Dai, H. Li, and K. Fan, "Direct hydro-alcohol thermal synthesis of special core-shell structured Fe-doped titania microspheres with extended visible light response and enhanced photoactivity," Applied Catalysis B, vol. 85, no. 3-4, pp. 162-170, 2009.

[39] E. Burstein, "Anomalous optical absorption limit in InSb," Physical Review, vol. 93, no. 3, pp. 632-633, 1954.

[40] T. S. Moss, "The interpretation of the properties of indium antimonide," Proceedings of the Physical Society B, vol. 67, no. 10, pp. 775-782, 1954.

[41] B. E. Sernelius, K. F. Berggren, Z. Jin, I. Hamberg, and C. G. Granqvist, "Band-gap tailoring of $\mathrm{ZnO}$ by means of heavy $\mathrm{Al}$ doping," Physical Review B, vol. 37, no. 8, pp. 10244-10248, 1998.

[42] M. N. Norazia, N. P. Ariyanto, A. A. Khadum, S. Shaari, H. Abdullah, and C. F. Dee, "Structural, morphology and optical properties of $\mathrm{Zn}_{1-\mathrm{x}} \mathrm{Sn}_{\mathrm{x}} \mathrm{O}$ ( $\mathrm{x}=0.0,0.1$ and 0.2 ) thin films by sol-gel method," Solid State Science and Technology, vol. 18, no. 1, pp. 202-211, 2010.

[43] J. G. Yu, Q. J. Xiang, and M. H. Zhou, "Preparation, characterization and visible-light-driven photocatalytic activity of Fe-doped titania nanorods and first-principles study for electronic structures," Applied Catalysis B, vol. 90, no. 3-4, pp. 595-602, 2009.

[44] R. C. Xiong, C. G. Jia, and G. Wei, "Treatment of dyestuffs wastewater with two and three-dimension electrode methods," Journal of Beijing University of Chemical Technology, vol. 29, no. 5, pp. 34-37, 2002.

[45] X. Li, R. Xiong, and G. Wei, "Preparation and photocatalytic activity of nanoglued Sn-doped $\mathrm{TiO}_{2}$," Journal of Hazardous Materials, vol. 164, no. 2-3, pp. 587-591, 2009.

[46] J. G. Yu, J. F. Xiong, B. Cheng, and S. W. Liu, "Fabrication and characterization of $\mathrm{Ag}-\mathrm{TiO}_{2}$ multiphase nanocomposite thin films with enhanced photocatalytic activity," Applied Catalysis $B$, vol. 60, no. 3-4, pp. 211-221, 2005.

[47] B. F. Xin, D. D. Ding, Y. N. Gao, X. G. Jin, H. Fu, and P. Wang, "Preparation of nanocrystalline $\mathrm{Sn}-\mathrm{TiO}_{2}-\mathrm{X}$ via a rapid and simple stannous chemical reducing route," Applied Surface Science, vol. 255, no. 11, pp. 5896-5901, 2009.

[48] Z. Xiufeng, L. Juan, L. Lianghai, and W. Zuoshan, "Preparation of crystalline Sn-doped $\mathrm{TiO}_{2}$ and its application in visible-light photocatalysis," Journal of Nanomaterials, vol. 2011, Article ID 432947, 5 pages, 2011.

[49] J. Shang, W. Q. Yao, Y. F. Zhu, and N. Z. Wu, "Structure and photocatalytic performances of glass $/ \mathrm{SnO}_{2} / \mathrm{TiO}_{2}$ interface composite film," Applied Catalysis A, vol. 257, no. 1, pp. 25-32, 2004.

[50] M. L. Chen and W. C. Oh, "The improved photocatalytic properties of methylene blue for $\mathrm{V}_{2} \mathrm{O}_{3} / \mathrm{CNT} / \mathrm{TiO}_{2}$ composite under visible light," International Journal of Photoenergy, vol. 2010, Article ID 264831, 5 pages, 2011.

[51] J. G. Yu, X. J. Zhao, J. C. Du, and W. M. Chen, "Preparation, microstructure and photocatalytic activity of the porous $\mathrm{TiO}_{2}$ anatase coating by sol-gel processing," Journal of Sol-Gel Science and Technology, vol. 17, no. 2, pp. 163-171, 2000.

[52] M. Zhou, J. Yu, and B. Cheng, "Effects of Fe-doping on the photocatalytic activity of mesoporous $\mathrm{TiO}_{2}$ powders prepared by an ultrasonic method," Journal of Hazardous Materials, vol. 137, no. 3, pp. 1838-1847, 2006.

[53] M. A. Behnajady, N. Modirshahla, M. Shokri, and B. Rad, "Enhancement of photocatalytic activity of $\mathrm{TiO}_{2}$ nanoparticles by silver doping: photodeposition versus liquid impregnation methods," Global NEST Journal, vol. 10, no. 1, pp. 1-7, 2008.

[54] O. Carp, C. L. Huisman, and A. Reller, "Photoinduced reactivity of titanium dioxide," Progress in Solid State Chemistry, vol. 32, no. 1-2, pp. 33-177, 2004.

[55] H. M. Coleman, K. Chiang, and R. Amal, "Effects of Ag and Pt on photocatalytic degradation of endocrine disrupting chemicals in water," Chemical Engineering Journal, vol. 113, no. 1, pp. 65-72, 2005.

[56] N. Sobana, M. Muruganadham, and M. Swaminathan, "NanoAg particles doped $\mathrm{TiO}_{2}$ for efficient photodegradation of Direct azo dyes," Journal of Molecular Catalysis A, vol. 258, no. 1-2, pp. 124-132, 2006.

[57] M. A. Behnajady, N. Modirshahla, and R. Hamzavi, "Kinetic study on photocatalytic degradation of C.I. Acid Yellow 23 by ZnO photocatalyst," Journal of Hazardous Materials, vol. 133, no. 1-3, pp. 226-232, 2006.

[58] Z. M. El-Bahy, A. A. Ismail, and R. M. Mohamed, "Enhancement of titania by doping rare earth for photodegradation of organic dye (Direct Blue)," Journal of Hazardous Materials, vol. 166, no. 1, pp. 138-143, 2009.

[59] O. Legrini, E. Oliveros, and A. M. Braun, "Photochemical processes for water treatment," Chemical Reviews, vol. 93, no. 2, pp. 671-698, 1993.

[60] J. C. Sin, S. M. Lam, A. R. Mohamed, and K. T. Lee, "Degrading endocrine disrupting chemicals from wastewater by $\mathrm{TiO}_{2}$ photocatalysis: a review," International Journal of Photoenergy, vol. 2012, Article ID 185159, 23 pages, 2012.

[61] N. Daneshvar, D. Salari, and A. R. Khataee, "Photocatalytic degradation of azo dye acid red 14 in water: investigation of the effect of operational parameters," Journal of Photochemistry and Photobiology A, vol. 157, no. 1, pp. 111-116, 2003.

[62] A. Mills and S. Morris, "Photomineralization of 4-chlorophenol sensitized by titanium dioxide: a study of the initial kinetics of carbon dioxide photogeneration," Journal of Photochemistry and Photobiology A, vol. 71, no. 1, pp. 75-83, 1993.

[63] N. Barka, S. Qourzal, A. Assabbane, and Y. Ait-Ichou, "Kinetic modeling of the photocatalytic degradation of methyl orange by supported $\mathrm{TiO}_{2}$," Journal of Environmental Science and Engineering, vol. 4, no. 5, pp. 1-5, 2010. 


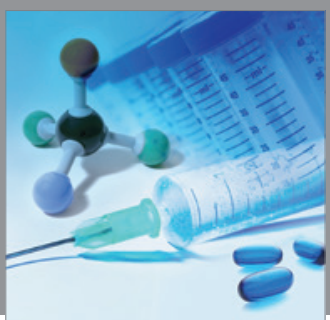

International Journal of

Medicinal Chemistry

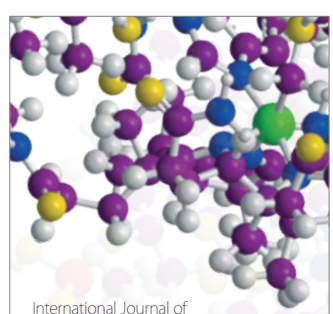

Carbohydrate Chemistry

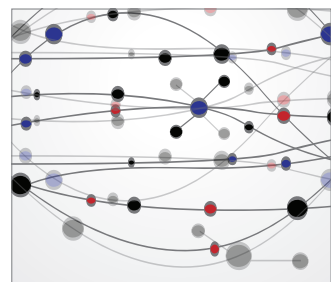

The Scientific World Journal
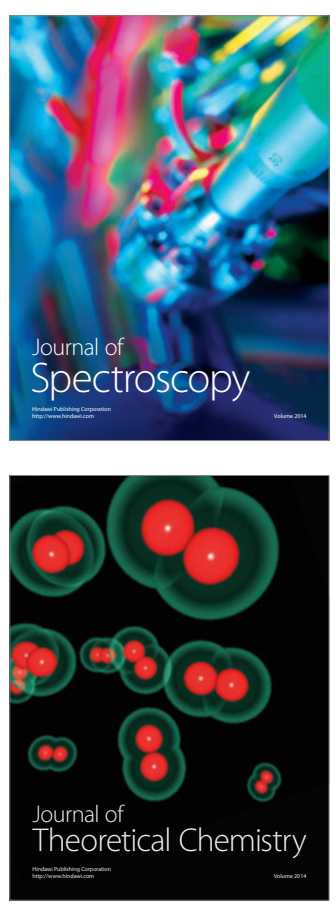
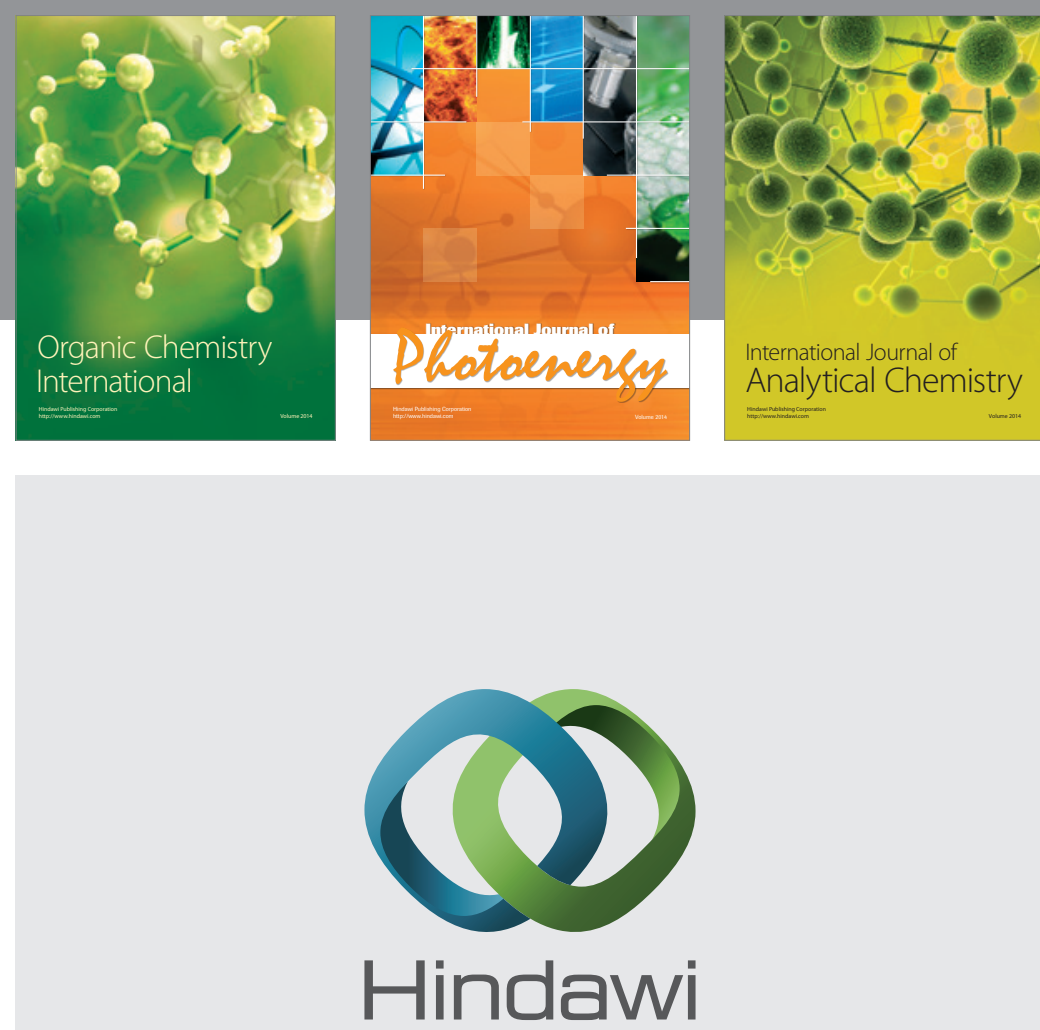

Submit your manuscripts at

http://www.hindawi.com
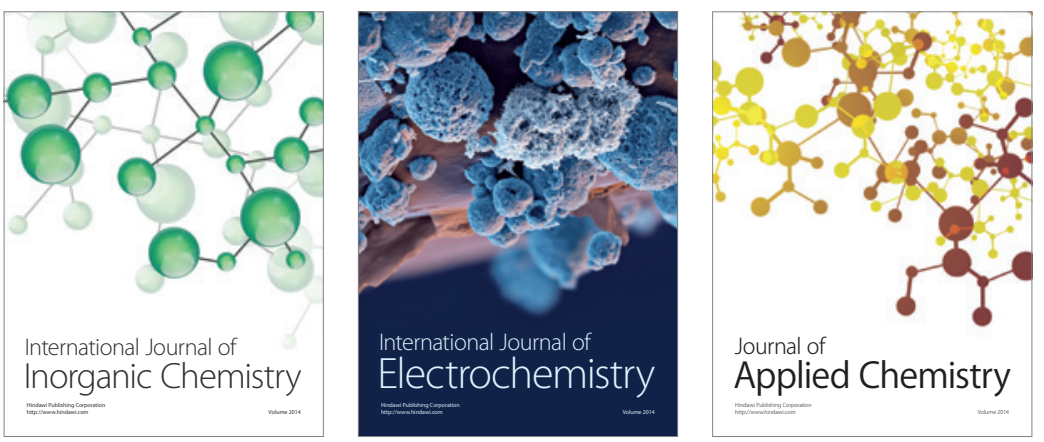

Journal of

Applied Chemistry
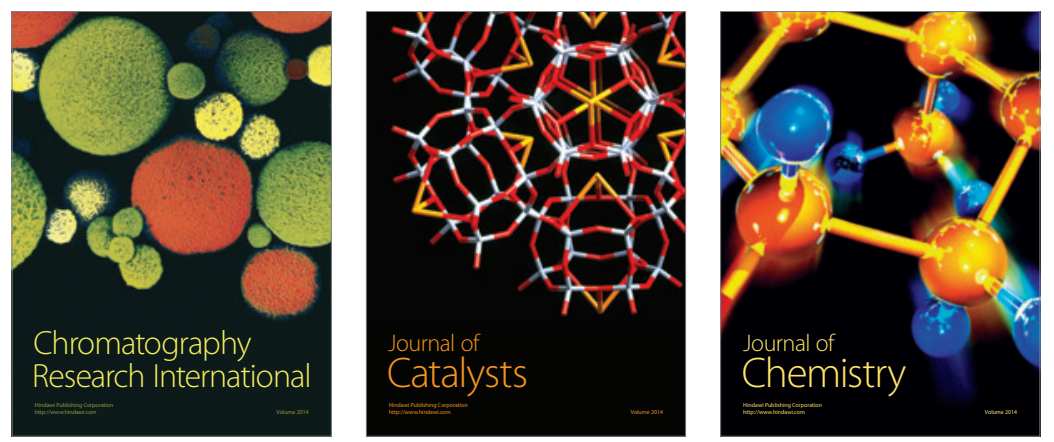
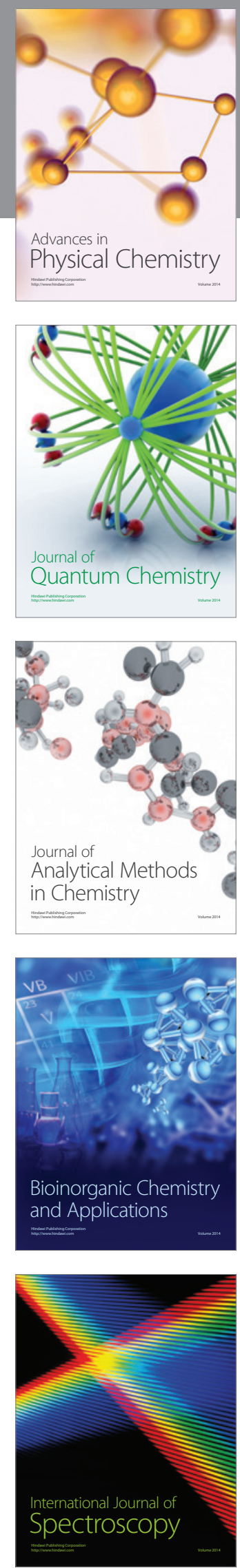